\title{
Poplar-type propolis provides protection of blood cells, testosterone levels and sperm motility in cisplatin-induced toxicity
}

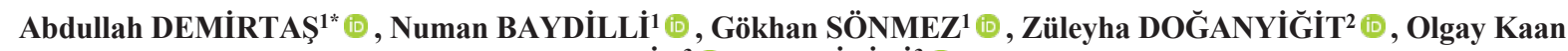

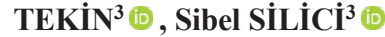

${ }^{1}$ Department of Urology, Medical Faculty, Erciyes University, Kayseri, Turkey

${ }^{2}$ Department of Histology and Embryology, Medical Faculty, Bozok University, Yozgat, Turkey

${ }^{3}$ Department of Agricultural Biotechnology; Seyrani Agriculture Faculty, Erciyes University, Kayseri, Turkey

\begin{abstract}
\begin{tabular}{ccccc}
\hline Received: 04.03 .2021 & $\bullet$ & Accepted/Published Online: 07.03.2021 & • Final Version: 30.08 .2021 \\
\hline
\end{tabular}
\section{Abstract}

Cisplatin is a frequently used chemotherapeutic in many types of cancer, especially urological cancers. Despite its efficacy in the treatment of cancer, it causes various toxic side effects such as nephrotoxicity, neurotoxicity and ototoxicity. The aim of this study was to determine the protective role of olive oil extract of propolis (OEP) with biochemical and histopathological approaches to cisplatin induced toxicity. Sixty-four adult male Wistar rats were divided into eight groups, control, propolis (100 and $200 \mathrm{mg} / \mathrm{kg}$, orally daily for 10 days) and combined therapy (propolis 10 days before and after CP injection). Haematological (Wbc, Rbc, Mpv, Hgb, Htc, Mcv, Mch, Mchc, Lym, Neu), biochemical (triglyceride, total cholesteol, HDL and LDL-cholesterol, glucose, BUN, uric acid and testosterone level), epididymal sperm concentration, sperm motility, and histological parameters were analyzed. According to the results, cisplatin has negative effects on hematological, biochemical parameters, and sperm motility compared to control group. Administration of pre-cisplatin propolis ameliorated wbc, hct, mcv, mchc, neu levels. The administration of OEP prior to CP normalized the increased BUN and uric acid levels induced by $\mathrm{CP}$. Interestingly it was also revealed that the testosterone levels increased in the OEP groups compared to the control group. Additionally, the combined administration of CP with OEP normalized the decreased testosterone levels induced by $\mathrm{CP}$, particularly pre-treatment OEP. As a result, propolis, a natural product with numerous useful biological effects, was shown to a have protective as well as amelioration and normalizing effect on CP-induced damage.
\end{abstract}

Keywords: biochemical parameters, cisplatin, heamatological, propolis, sperm

\section{Introduction}

Cisplatin (CP; cis-diamminedichloroplatinum (II)) is an effective agent widely used in the treatment of numerous solid tumors (testis, bladder, breast, or ovarian cancer, etc.). After entering the cell, CP interacts with DNA, thereby leading to local denaturation of the DNA chain, inhibiting ATPase activity, modifying the cellular transport system, and ultimately causing apoptosis, inflammation, necrosis, and death in cells $(1,2)$. High CP concentrations lead to necrosis in the proximal tubular cells and low concentrations lead to apoptosis (3). Moreover, despite its clinical benefits, CP therapy has been shown to have several adverse effects including nephrotoxicity, neurotoxicity, and ototoxicity (4).

It is commonly known that many plants protect their leaves, flowers, fruits, and buds from frost and bacterial invasion by producing a potent antimicrobial, waterproof, and heat-resistant resinous substance. This substance, termed 'propolis', is collected by honeybees (Apis mellifera L.) with the aid of their mandibular glands and mixed with secretions from the mandibular and wax glands to form pellets and are then carried to the hive. Raw propolis cannot be used in food and pharmacology industries; therefore, it is subjected to extraction with ethyl alcohol, propylene glycol, glycerol, and water. However, because of the limited use of alcohol due to religious beliefs and in children and patients with alcohol intolerance and metabolic diseases, researchers have recently tested water and oil extracts of propolis (OEP) (5). Propolis typically has numerous biological and pharmacological properties such as immunomodulatory, antitumoral, antiinflammatory, antioxidant, antibacterial, antiviral, antifungal, and antiparasitic activities (6-8). Additionally, OEP have been shown to have antimicrobial, antitumoral, antioxidant, and antidepressant properties $(9,10)$.

In the present study, we aimed to investigate the potential protective role of olive oil-propolis (poplar-type) extract (OEP) against CP-induced toxicity.

\section{Materials and methods}

\subsection{High-performance liquid chromatography (HPLC) analysis of propolis}

Detection of phenolic acids was performed using HighPerformance Liquid Chromatography (HPLC). The analysis 
of samples was performed with an Agilent 1100 HPLC system equipped with a photodiode array detector and an iontrap mass spectrometer detector (Agilent Technologies, Waldbronn, Germany). The mobile phase of the method consisted of Solvent A (methanol) and Solvent B (0.5\% (v/v) acetic acid in water). The elution profile was $10 \% \mathrm{~A}$ in $\mathrm{B}, 0$ $\min ; 60 \% \mathrm{~A}$ in $\mathrm{B}, 28 \mathrm{~min}$; and $10 \% \mathrm{~A}$ in $\mathrm{B}, 30 \mathrm{~min}$. All the gradients were linear. A volume of $10 \mu \mathrm{L}$ of sample was injected onto the column operating at room temperature at a flow rate of $1 \mathrm{~mL} / \mathrm{min}$. Ultraviolet (UV) detection was performed at $290 \mathrm{~nm}$ and UV chromatograms were recorded at 280 and $360 \mathrm{~nm}$ with a bandwidth of $8 \mathrm{~nm}$. The eluted components were identified based on the retention time by comparison with the retention time of the reference standard.

\subsection{Administrations of propolis and cisplatin}

The olive oil-propolis (poplar type) extract used in the study (25\% propolis) was manufactured by Nutral Therapy Ltd., Kayseri, Turkey. Propolis was administered orally at doses of 100 and $200 \mathrm{mg}$ using an oral cannula. Cisplatin (SigmaAldrich, USA) injection was administered intraperitoneally according to the body weight of the rats in a single dose of 7 $\mathrm{mg} / \mathrm{kg}$.

\subsection{Animals and experimental design}

A total of 64 adult male Wistar albino rats weighing 250-260 $\mathrm{g}$ were used in the study. The animals were kept in a special room at a constant temperature of $22^{\circ} \mathrm{C} \pm 1^{\circ} \mathrm{C}$ with 12-hour light/dark cycles and had free access to food and tap water. The study protocol was approved by the Animal Care and Use Committee at Erciyes University School of Medicine. All the experimental procedures were conducted in accordance with the Guide to the Care and Use of Laboratory Animals. The 64 rats were randomly divided into 8 groups with 8 rats each: (I) Control group; $0.9 \%$ saline $(10 \mathrm{mg} / \mathrm{kg})$ was injected i.p through the tail vein of the rats, (II) CP group (CP); a single dose of CP (7 mg/kg) was injected i.p., (III) OEP 1 group (OEP1); OEP was given orally once a day at a dose of 100 $\mathrm{mg} / \mathrm{kg}$ for 10 days, (IV) OEP 2 group (OEP2); OEP was given orally once a day at a dose of $200 \mathrm{mg} / \mathrm{kg}$ for 10 days, (V) CP + OEP 1 group (CP+OEP1): a single dose of CP was injected i.p. and OEP was given orally once a day at a dose of $100 \mathrm{mg} / \mathrm{kg}$ for 10 days, (VI) CP + OEP 2 group (CP+OEP2): a single dose of CP was injected i.p and OEP was given orally once a day at a dose of $200 \mathrm{mg} / \mathrm{kg}$ for 10 days, (VII) OEP $1+$ $\mathrm{CP}$ group $(\mathrm{OEP} 1+\mathrm{CP})$; OEP was given orally once a day at a dose of $100 \mathrm{mg} / \mathrm{kg}$ for 10 days and then a single dose of CP (7 $\mathrm{mg} / \mathrm{kg}$ ) was injected, and (VIII) OEP $2+\mathrm{CP}$ group $(\mathrm{OEP} 2+\mathrm{CP})$; OEP was given orally once a day at a dose of $200 \mathrm{mg} / \mathrm{kg}$ for 10 days and then a single dose of CP $(7 \mathrm{mg} / \mathrm{kg})$ was injected.

\subsection{Sample collection}

The animals were fasted for $6 \mathrm{~h}$ before the collection of testis tissue and blood samples. The animals were maintained under light ether anesthesia which was induced immediately before the collection of blood samples, and samples were collected from each animal by insertion of a cannula in the heart and then transferred into tubes both with and without anticoagulants. Blood samples were obtained from all 8 animals in each group and were centrifuged at $3.000 \mathrm{~g}$ for 10 min. Testis samples were cleared from adhering connective tissue and weighed. One testis was fixed in 10\% formalin for histopathologic examination. Plasma and other testis samples were stored at $-20^{\circ} \mathrm{C}$ until biochemical analysis. The blood parameters analyzed included white blood cells (WBC), red blood cells (RBC), hemoglobin (HGB), hematocrit (HCT), nucleated red blood cells (NRBC), mean platelet volume (MPV), mean corpuscular volume (MCV), mean corpuscular hemoglobin $(\mathrm{MCH})$, mean corpuscular hemoglobin concentration (MCHC), and lymphocyte (LYM) and neutrophil (NEU) counts. Serum was separated and used for the analysis of certain biochemical parameters. A Konelab 60i auto-analyzer (Thermo Clinical Labsystems, Finland) and a Konelab label kit (Thermo Clinical Labsystems, Finland) were used for the determination of serum glucose (GLU), creatinine (CRE), uric acid, triglyceride (TRIG), total cholesterol (CHOL), LDL-cholesterol (LDL-CHOL), and HDL-Cholesterol (HDL-CHOL) levels.

\subsection{Epididymal sperm concentration and motility}

The epididymis was finely minced with anatomic scissors in 5 $\mathrm{mL}$ of physiological saline, placed in a rocker for $10 \mathrm{~min}$, and incubated at room temperature for $2 \mathrm{~min}$. After incubation, the supernatant fluid was diluted at a ratio of 1:100 with a solution containing $5 \mathrm{~g}$ sodium bicarbonate, $1 \mathrm{~mL}$ formalin (35\%), and $25 \mathrm{mg}$ eosin per $100 \mathrm{~mL}$ of distilled water. Total number of sperms was determined with a hemocytometer. Approximately $10 \mathrm{~mL}$ of the diluted sperm suspension was transferred to each counting chamber and could stand for five min for counting under a light microscope at 200x magnification. Sperm progressive motility was evaluated by a method described earlier (11). For this purpose, fluid was obtained from the caudal epididymis with a pipette and diluted to $2 \mathrm{~mL}$ with Tris's buffer solution. The system was prewarmed $\left(35^{\circ} \mathrm{C}\right)$ and the percentage of motility was evaluated visually at $400 \mathrm{x}$ magnification. Motility estimations were performed from 3 different fields in each sample. The mean value was used as the final motility score.

\subsection{Histopathologic examination}

Testis samples were fixed in $10 \%$ formaldehyde solution and then embedded in paraffin blocks after being subjected to routine tissue processing sequences. Sections of 5-6 $\mu \mathrm{m}$ thickness were prepared from the paraffin blocks and mounted on glass slides. The slides were incubated for a certain period using histological techniques, deparaffinized through xylene, and hydrated with a graded series of alcohol. The sections were stained with hematoxylin-eosin (H\&E) staining for general histologic features. Histopathological examination of the testis samples was achieved in 50 areas using Johnsen's mean testicular biopsy score (MTBS) criterion under an Olympus BX51 microscope (12). 
Data were analyzed using SPSS for Windows version 22.0 (IBM SPSS Statistics for Windows, Armonk, NY: IBM Corp.). Descriptive were expressed as mean \pm standard deviation (SD). Groups were compared using One-Way ANOVA followed by post-hoc Tukey test. A $p$ value of $<0.05$ was considered significant. All procedures performed in studies involving animals were in accordance with the ethical standards of the institution or practice at which the studies were conducted (Approval number: 17/029)

\section{Results}

Fig. 1 presents the chemical composition of OEP. Caffeic acid phenethyl ester (CAPE; an active component of honeybee propolis) had the highest concentration, followed by dimethoxycinnamic acid, caffeic acid, ferulic acid, pcoumaric acid, and vanillin.

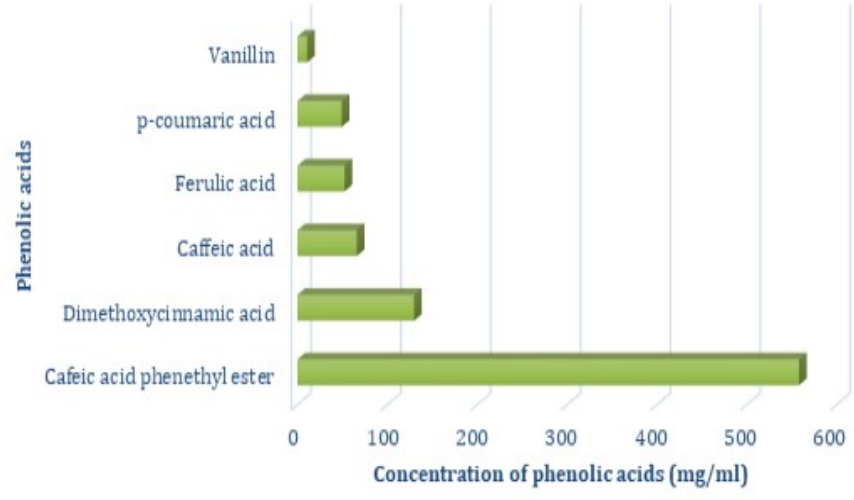

Fig.1. Chemical composition of OEP

\subsection{Changes in Hematological Parameters}

In terms of WBC, significant difference was observed in the group administered $\mathrm{CP}$ compared to the control group. While WBC levels were decreased in the groups that received $\mathrm{CP}$, $\mathrm{OEP} 1+\mathrm{CP}$ and $\mathrm{CP}+\mathrm{OEP} 1$, an increase was found in the other groups near the control group $(p<0.01)$. In terms of $\mathrm{RBC}$, the highest $\mathrm{RBC}$ levels were observed in the $\mathrm{CP}$ group and the lowest in the control group and a significant difference was found among the experimental groups $(p<0.01)$. In particular, the improvement in the groups that were administered OEP prior to CP was highly remarkable and a significant difference was found among the groups $(p<0.05)$.

In terms of MPV, no significant difference was found among the groups and the CP group had the lowest MPV level. Additionally, a remarkable improvement was observed in all the OEP groups, although no significant difference was found among the OEP groups $(p>0.05)$. On the other hand, the administration of $\mathrm{CP}$ decreased the HGB levels while the administration of OEP increased the HGB levels; however, no significant difference was found among the CP groups $(p<0.01)$. The administration of OEP resulted in similar HCT levels to those of the control group and this improvement was statistically significant $(p<0.05)$. No significant difference was found among the groups about $\mathrm{MCH}$ levels although a numerical improvement was observed in the OEP2 groups. A significant difference was found among the groups about MCV levels, with the lowest MCV levels found in the CP group and no significant improvement observed among the OEP2 groups. In the groups administered a combination of $\mathrm{CP}$ and OEP, the results were similar to those of the control group although this improvement was not statistically significant $(p>0.05)$. MCHC levels were higher in the OEP2 groups compared to the control group and this improvement was particularly more noticeable in the $\mathrm{OEP} 2+\mathrm{CP}$ group. The LYM counts in the OEP groups were similar to those of the control group when compared to the CP group and the neutrophil counts were significantly improved in all groups except for the OEP $1+\mathrm{CP}$ group $(\mathrm{p}<0.05)$. Table 1 presents the changes in hematological parameters in the groups administered with a combination of $\mathrm{CP}$ and OEP.

\subsection{Changes in biochemical parameters}

Administration of CP led to increased triglyceride and LDLcholesterol levels and decreased HDL-Cholesterol levels, although no significant difference was established among the groups $(p>0.05)$. However, a significant difference was found among the groups about cholesterol levels, with the highest cholesterol levels found in the CP group. Additionally, the cholesterol levels in the groups administered a combination of OEP and CP were decreased to those of the control group. In terms of glucose levels, a remarkable decrease was found in the OEP groups compared to the control group and the improvement in the glucose levels in the groups administered a combination of OEP and CP was statistically significant $(p<0.05)$. On the other hand, no significant difference was found among the OEP groups with regard to blood urea nitrogen (BUN) levels, whereas the BUN levels in the OEP2 group implicated that the administration of OEP reduced the CP-induced increase in BUN levels $(p<0.05)$. The uric acid levels in the CP group were significantly higher than those of other groups and a significant decrease was observed in the uric acid levels in the OEP $2+\mathrm{CP}$ group. The testosterone levels in the OEP groups were higher than those of the control group, although no significant difference was established. However, it was revealed that the administration of OEP prior to $\mathrm{CP}$ had a normalizing effect on the decreased testosterone levels induced by CP. Table 2 presents the changes in biochemical parameters in the groups administered with a combination of CP and OEP.

\subsection{Comparison of sperm parameters}

Although no significant difference was observed among the groups about epididymal sperm concentration, a significant difference was found about sperm motility. A remarkable improvement was found in sperm motility in the groups administered OEP prior to CP (Fig. 2).

\subsection{Histopathological evaluation results}

Normal histological structure was observed in the control group. The OEP2 group and the groups administered a combination of $\mathrm{CP}$ and OEP showed nearly normal histological structure, whereas the CP group showed 
significantly decreased MTBS compared to the control group.

Table 1. Hematological parameters measured before and after the administration of $\mathrm{CP}$

\begin{tabular}{|c|c|c|c|c|c|}
\hline Groups & $\mathrm{WBC}\left(10^{3} / \mathrm{mm}^{3}\right)$ & $\operatorname{RBC}\left(10^{6} / \mathrm{mm}^{3}\right)$ & MPV & $\begin{array}{l}\text { HGB } \\
\text { (g/dL) }\end{array}$ & $\begin{array}{l}\text { HCT } \\
(\%)\end{array}$ \\
\hline Control & $11.33 \pm 1.3^{b}$ & $9.31 \pm 0.4^{\mathrm{d}}$ & $7.44 \pm 0.3^{c}$ & $16.23 \pm 04^{b}$ & $53.15 \pm 1.1^{\mathrm{c}}$ \\
\hline OEP1 & $9.88 \pm 1.2^{\mathrm{b}}$ & $8.65 \pm 0.4^{\mathrm{bcd}}$ & $7.32 \pm 0.2^{\mathrm{bc}}$ & $15.50 \pm 0.7^{\mathrm{ab}}$ & $47.62 \pm 4.2^{\mathrm{ab}}$ \\
\hline $\mathrm{OEP} 1+\mathrm{CP}$ & $6.34 \pm 1.3^{\mathrm{a}}$ & $8.56 \pm 0.6^{\mathrm{bcd}}$ & $7.10 \pm 0.4^{\mathrm{abc}}$ & $15.35 \pm 1.3^{\mathrm{ab}}$ & $46.46 \pm 2.1^{\mathrm{ab}}$ \\
\hline $\mathrm{CP}+\mathrm{OEP} 1$ & $6.37 \pm 2.2^{\mathrm{a}}$ & $8.34 \pm 0.4^{\mathrm{ab}}$ & $6.95 \pm 0.3^{\mathrm{ab}}$ & $15.02 \pm 0.6^{\mathrm{ab}}$ & $45.58 \pm 2.3^{\mathrm{ab}}$ \\
\hline OEP2 & $10.62 \pm 1.2^{b}$ & $9.18 \pm 0.3^{\mathrm{cd}}$ & $7.38 \pm 0.2^{\mathrm{bc}}$ & $16.23 \pm 0.4^{b}$ & $53.33 \pm 2.13^{c}$ \\
\hline $\mathrm{OEP} 2+\mathrm{CP}$ & $9.66 \pm 1.4^{\mathrm{b}}$ & $8.42 \pm 0.2^{\mathrm{abc}}$ & $7.20 \pm 0.1^{\mathrm{abc}}$ & $15.27 \pm 0.7^{\mathrm{ab}}$ & $49.68 \pm 2.5^{\mathrm{bc}}$ \\
\hline $\mathrm{CP}+\mathrm{OEP} 2$ & $9.79 \pm 1.4^{\mathrm{b}}$ & $8.09 \pm 0.6^{\mathrm{ab}}$ & $7.15 \pm 0.4^{\mathrm{abc}}$ & $14.23 \pm 0.8^{\mathrm{a}}$ & $46.07 \pm 1.3^{\mathrm{ab}}$ \\
\hline $\mathrm{CP}$ & $4.88 \pm 1.3^{\mathrm{a}}$ & $7.64 \pm 0.9^{\mathrm{a}}$ & $6.78 \pm 0.2^{\mathrm{a}}$ & $14.18 \pm 1.4^{\mathrm{a}}$ & $44.34 \pm 4.8^{\mathrm{a}}$ \\
\hline Control & $58.10 \pm 1.13^{c}$ & $18.58 \pm 0.4^{b}$ & $32.23 \pm 0.3^{\mathrm{c}}$ & $65.48 \pm 1.3^{\mathrm{a}}$ & $16.0 \pm 4.8^{\mathrm{a}}$ \\
\hline OEP1 & $57.40 \pm 1.02^{\mathrm{bc}}$ & $18.12 \pm 0.7^{\mathrm{ab}}$ & $32.32 \pm 0.1^{\mathrm{c}}$ & $79.48 \pm 5.3^{b}$ & $15.95 \pm 3.9^{\mathrm{a}}$ \\
\hline $\mathrm{OEP} 1+\mathrm{CP}$ & $55.72 \pm 1.09^{\mathrm{ab}}$ & $17.68 \pm 0.5^{\mathrm{a}}$ & $31.23 \pm 0.8^{\mathrm{ab}}$ & $82.97 \pm 3.7^{\mathrm{bc}}$ & $15.56 \pm 2.7^{\mathrm{a}}$ \\
\hline $\mathrm{CP}+\mathrm{OEP} 1$ & $55.60 \pm 1.92^{\mathrm{ab}}$ & $17.58 \pm 0.4^{\mathrm{a}}$ & $30.53 \pm 0.6^{\mathrm{a}}$ & $83.43 \pm 2.7^{b c}$ & $22.96 \pm 1.7^{\mathrm{ab}}$ \\
\hline OEP2 & $57.95 \pm 1.20^{c}$ & $18.22 \pm 0.5^{\mathrm{ab}}$ & $33.15 \pm 0.9^{d}$ & $74.44 \pm 9.3^{b}$ & $15.13 \pm 4.8 \mathrm{a}$ \\
\hline $\mathrm{OEP} 2+\mathrm{CP}$ & $57.30 \pm 0.60^{\mathrm{bc}}$ & $17.92 \pm 0.5^{\mathrm{ab}}$ & $31.98 \pm 0.3^{b c}$ & $81.60 \pm 3.9^{\mathrm{bc}}$ & $15.38 \pm 2.7^{\mathrm{a}}$ \\
\hline $\mathrm{CP}+\mathrm{OEP} 2$ & $56.45 \pm 2.08^{\mathrm{abc}}$ & $17.93 \pm 0.3^{\mathrm{ab}}$ & $31.22 \pm 0.8^{\mathrm{ab}}$ & $83.44 \pm 2.3^{\mathrm{bc}}$ & $16.93 \pm 2.7^{\mathrm{a}}$ \\
\hline $\mathrm{CP}$ & $54.70 \pm 0.84^{\mathrm{a}}$ & $17.45 \pm 0.3^{\mathrm{a}}$ & $30.43 \pm 0.6^{\mathrm{a}}$ & $84.73 \pm 4.4^{c}$ & $30.23 \pm 1.9^{b}$ \\
\hline
\end{tabular}

Values are expressed as mean, SD; $<<0.05$; CP: Cisplatin, OEP: Olive oil extract of propolis. a, b, c, d. The groups in the same column with different letters are statistically different

On the other hand, seminiferous tubule diameter was significantly decreased in the $\mathrm{CP}, \mathrm{OEP} 1, \mathrm{OE} 2$, and $\mathrm{CS}+\mathrm{OEP} 2$ groups and was insignificantly decreased in the $\mathrm{OEP} 1+\mathrm{CP}$, $\mathrm{OEP} 2+\mathrm{CP}$, and $\mathrm{CP}+\mathrm{OEP} 1$ groups compared to the control group $(\mathrm{p}<0.001)$. The histopathological results were shown in Table 3 and Fig. 3.

\section{Discussion}

The present study was designed to investigate the effect of $\mathrm{CP}$ supplementation with propolis on hematological parameters such as WBC and anemia indices in Wistar albino rats. The results revealed significant differences in various hematological parameters in the experimental groups compared to the control and the $\mathrm{CP}$ group. The results also implicated that hemolytic anemia could result from $\mathrm{CP}$ and this is likely to be associated with the reaction of an antibody directed against red cell membrane-bound CP. Anemia has been shown to be a common side effect of $\mathrm{CP}$, with its primary mechanism to be a myelosuppression resulting from CP's interference with iron metabolism, thereby leading to a lower count of red cell precursors (13). The examination of hematological parameters in our study indicated a significant difference among the groups in terms of $\mathrm{RBC}$ and $\mathrm{MCHC}$ $(p<0.05)$. Moreover, WBC counts were significantly increased in the $\mathrm{CP}$ group compared to the control group $(p<0.05)$ and were like those of the control group in the OEP groups.

Table 2. Biochemical parameters measured before and after the administration of CP

\begin{tabular}{|l|c|c|c|c|}
\hline Groups & Triglyceride (mg/dL) & Total Cholesterol $\mathbf{( m g / d L )}$ & HDL Cholesterol (mg/dL) & LDL Cholesterol (mg/dL) \\
\hline Control & $95.5 \pm 20.5$ & $51.33 \pm 7.6^{\mathrm{a}}$ & $40.46 \pm 5.23$ & $4.7 \pm 0.6$ \\
\hline OEP1 & $95.0 \pm 34.2$ & $52.75 \pm 4.2^{\mathrm{a}}$ & $53.39 \pm 5.4$ & $4.4 \pm 1.3$ \\
\hline OEP1+CP & $108.75 \pm 24.3$ & $55.33 \pm 9.6^{\mathrm{a}}$ & $34.97 \pm 3.1$ & $7.5 \pm 1.2$ \\
\hline CP+OEP1 & $123.20 \pm 37.2$ & $58.8 \pm 8.9^{\mathrm{a}}$ & $36.25 \pm 4.3$ & $7.4 \pm 1.3$ \\
\hline OEP2 & $93.83 \pm 34.5$ & $51.0 \pm 4.8^{\mathrm{a}}$ & $54.88 \pm 1.7$ & $4.2 \pm 0.7$ \\
\hline OEP2+CP & $106.17 \pm 32.0$ & $53.75 \pm 5.2^{\mathrm{a}}$ & $38.23 \pm 3.3$ & $7.0 \pm 1.0$ \\
\hline CP+OEP2 & $106.75 \pm 23.2$ & $57.33 \pm 4.4^{\mathrm{a}}$ & $36.17 \pm 6.1$ & $7.13 \pm 0.9$ \\
\hline CP & $132.33 \pm 31.1$ & $69.75 \pm 6.6^{\mathrm{b}}$ & $32.19 \pm 4.81$ & $8.0 \pm 0.8$ \\
\hline Control & $239.4 \pm 25.5^{\mathrm{ab}}$ & $15.50+0.20^{\mathrm{d}}$ & $19.0+2.82^{\mathrm{bc}}$ & $227.67 \pm 38.8^{\mathrm{b}}$ \\
\hline OEP1 & $214.83 \pm 30.0^{\mathrm{a}}$ & $17.38+0.29^{\mathrm{cd}}$ & $21.63+5.32^{\mathrm{abc}}$ & $282.0 \pm 12.7^{\mathrm{b}}$ \\
\hline OEP1+CP & $251.25 \pm 45.7^{\mathrm{ab}}$ & $24.33+1.08^{\mathrm{ab}}$ & $27.50+4.01^{\mathrm{abc}}$ & $198.83 \pm 14.2^{\mathrm{b}}$ \\
\hline CP+OEP1 & $282.25 \pm 32.6^{\mathrm{b}}$ & $26.20+1.83^{\mathrm{a}}$ & $29.50+2.90^{\mathrm{ab}}$ & $188.13 \pm 12.8^{\mathrm{a}}$ \\
\hline OEP2 & $213.5 \pm 26.9^{\mathrm{a}}$ & $13.14+0.42^{\mathrm{d}}$ & $16.25+1.32^{\mathrm{c}}$ & $288.17 \pm 14.1^{\mathrm{b}}$ \\
\hline OEP2+CP & $242 \pm 28.40^{\mathrm{ab}}$ & $17.32+0.84^{\mathrm{cd}}$ & $20.0+2.12^{\mathrm{bc}}$ & $215.47 \pm 15.4^{\mathrm{ab}}$ \\
CP+OEP2 & $252.00 \pm 46.8^{\mathrm{ab}}$ & $20.50+1.47^{\mathrm{bc}}$ & $23.83+4.82^{\mathrm{abc}}$ & $186.25 \pm 07.9^{\mathrm{a}}$ \\
CP & $280.25 \pm 30.65^{\mathrm{b}}$ & $26.40+1.72^{\mathrm{a}}$ & $32.14+1.52^{\mathrm{a}}$ & $69.88 \pm 06.4^{\mathrm{a}}$ \\
\hline
\end{tabular}

Values are expressed as mean $\pm \mathrm{SD} ; p<0.05$; CP: Cisplatin, OEP: Olive oil extract of propolis BUN: Blood urea nitrogen. ${ }^{\text {a,b,c,d }}$ The groups in the 
same column with different letters are statistically different

Table 3. Histopathological results of rat testis tissues

\begin{tabular}{|c|c|c|c|c|c|c|c|c|c|}
\hline Groups & Control & OEP1 & OEP2 & $\mathbf{C P}$ & OEP1+CP & OEP2+CP & CP+OEP1 & CP+OEP2 & $p$ \\
\hline MTBS & $9.60 \pm 0.49^{\mathrm{a}}$ & $8.86 \pm 1.02^{\mathrm{bd}}$ & $9.20 \pm 0.67^{\mathrm{ad}}$ & $6.73 \pm 0.82^{f}$ & $9.33 \pm 0.66^{\mathrm{ad}}$ & $8.30 \pm 0.87^{\text {bce }}$ & $8.93 \pm 0.94^{\text {abde }}$ & $7.96 \pm 1.42^{\mathrm{c}}$ & 0.001 \\
\hline $\begin{array}{c}\text { Seminifero } \\
\text { us tubular } \\
\text { diameter } \\
(\mu \mathrm{m})\end{array}$ & $310.22 \pm 35.58^{\mathrm{a}}$ & $272.60 \pm 39.76^{b}$ & $272.72 \pm 52.71^{b}$ & $258.84 \pm 23.33^{\mathrm{c}}$ & $284.62 \pm 33.8^{\mathrm{ab}}$ & $277.39 \pm 59.7^{\mathrm{ab}}$ & $278.2 \pm 41.1^{\mathrm{ab}}$ & $236.27 \pm 30.3^{c}$ & 0.001 \\
\hline
\end{tabular}

Values are expressed as mean $\pm \mathrm{SD} ; p<0.05$; CP: Cisplatin, OEP: Olive oil extract of propolis; MTBS: Johnsen's mean testicular biopsy score; a,b,c,d The groups with the same letter are statistically different

Additionally, although the administration of OEP both before and after $\mathrm{CP}$ administration resulted in similar levels to those of the control group, no significant difference was established. Lymphocyte levels were significantly increased in the $\mathrm{CP}$ groups compared to the control group. On the other hand, the analysis of anemia indices revealed that the HGB levels in the OEP groups were similar to those of the control group ( $p>0.05$ ). However, the CP group had decreased HGB levels compared to the control group. Hematocrit (HCT) indicates the volume of $\mathrm{RBC}$ compared to total blood volume. In other words, HCT is the percentage of cellular portion of blood to the liquid portion of blood. A low HCT level indicates anemia. MCV indicates the average size of RBC, whereas $\mathrm{MCH}$ indicates the weight of HGB in an average red cell. HGB indicates the amount of HGB present in blood while $\mathrm{MCH}$ indicates the amount of HGB in RBC alone. $\mathrm{MCHC}$ is the proportion of $\mathrm{MCH}$ to total amount of $\mathrm{RBC}$ independent of red cell count and size. In our study, CP had an adverse effect on blood parameters and the administration of OEP2 normalized the HCT, MCV, and MCHC levels. Meaningfully, since the administration of CP led to adverse effects on anemia indices, all the CP groups suffered anemia. This finding agrees with previous research results by Dufour et al (14). Similarly, CP causes oxidative stress in human platelets and lymphocytes, which might reflect on their life expectancy, induction of apoptosis, and ultimately reduce the number of these cells in the blood (15).

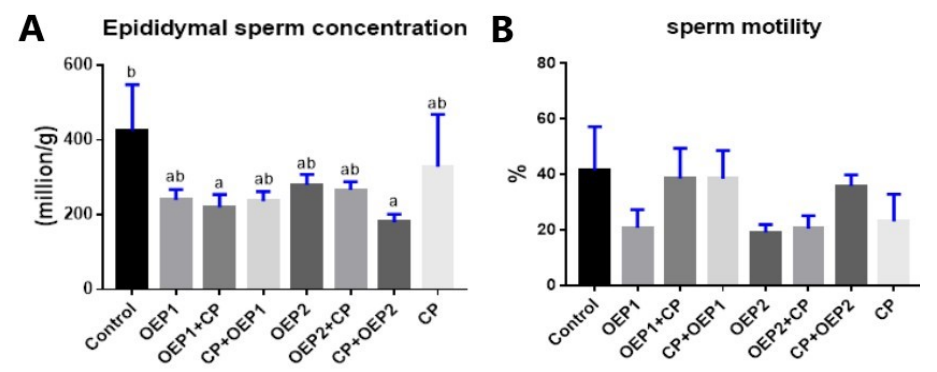

Fig. 2. (A) Epididymal sperm concentration of experimental groups, (B) Sperm motility of experimental groups

The biochemical analysis performed in our study indicated that both doses of OEP normalized the increased cholesterol levels induced by CP. Moreover, the administration of OEP prior to $\mathrm{CP}$ normalized the increased BUN and uric acid levels induced by $\mathrm{CP}$. Interestingly; however, it was also revealed that the testosterone levels increased in the OEP groups compared to the control group. Additionally, the combined administration of $\mathrm{CP}$ with OEP normalized the decreased testosterone levels induced by $\mathrm{CP}$, particularly in the groups administered OEP prior to CP. Propolis and its primary component, CAPE, have been shown to have antitumoral effects and to be effective on CP-induced toxicity. A previous study investigated the cytotoxic effects of ethanol extracts of Turkish propolis on human tumoral cell lines and reported that propolis showed high cytotoxic effect on five tumoral cell lines (16). Ibrahim administered CP both before and in combination with propolis in rats and reported that $\mathrm{CP}$ led to significantly decreased testicular weight, induced distorted seminiferous tubules, cellular disorganization, wide separation of intertubular space, cytoplasmic vacuolation, and pyknotic nuclei (17). Additionally, CP also increased the area of collagen fibers, increased optical density of nuclear factor-KB (NF-KB) immunoreactivity, and decreased the area of claudin 11 immuno-expression in the spermatogenic cells. The authors concluded that the blockade of NF-KB activation was achieved by propolis, and this activation could be an effective strategy for protection against CP-induced testicular damage if propolis is administered prior to the administration of $\mathrm{CP}$.

CAPE is an active component of poplar-type propolis with antioxidant, anti-inflammatory, antiviral, immunomodulatory and wound-healing acceleration properties (18). CAPE has been shown to completely block the production of reactive oxygen species (ROS) in human neutrophils at a concentration of $10 \mu \mathrm{mol}$, to protect liver against diabetic oxidative damage, to provide protection against $\mathrm{CP}$-induced hepatic and renal damage (19-22). Yilmaz et al. investigated the anticlastogenic effect of CAPE on CP-induced chromosome aberrations in rat bone marrow cells and reported that the administration of a single dose of CAPE led to a significant reduction in the total number of chromosomal aberrations and abnormal metaphases induced by CP (23). In addition, the total number of aberrations and abnormal metaphases was lower in the $\mathrm{CAPE}+\mathrm{CP}$ group compared to the $\mathrm{CP}$ group, although no significant difference was established. In another study, Tohamy et al. examined the anti-histopathologic, antioxidant, and anti-mutagenic effects of water extracts of bee pollen (140 mg/kg bw per day) and water-soluble derivative of propolis $(2.8 \mathrm{mg} / \mathrm{kg}$ bw per day) on CP-induced hepatic, renal, testicular toxicity, and 
genotoxicity in mice and on the oxidant/antioxidant status in the tested organs (24).

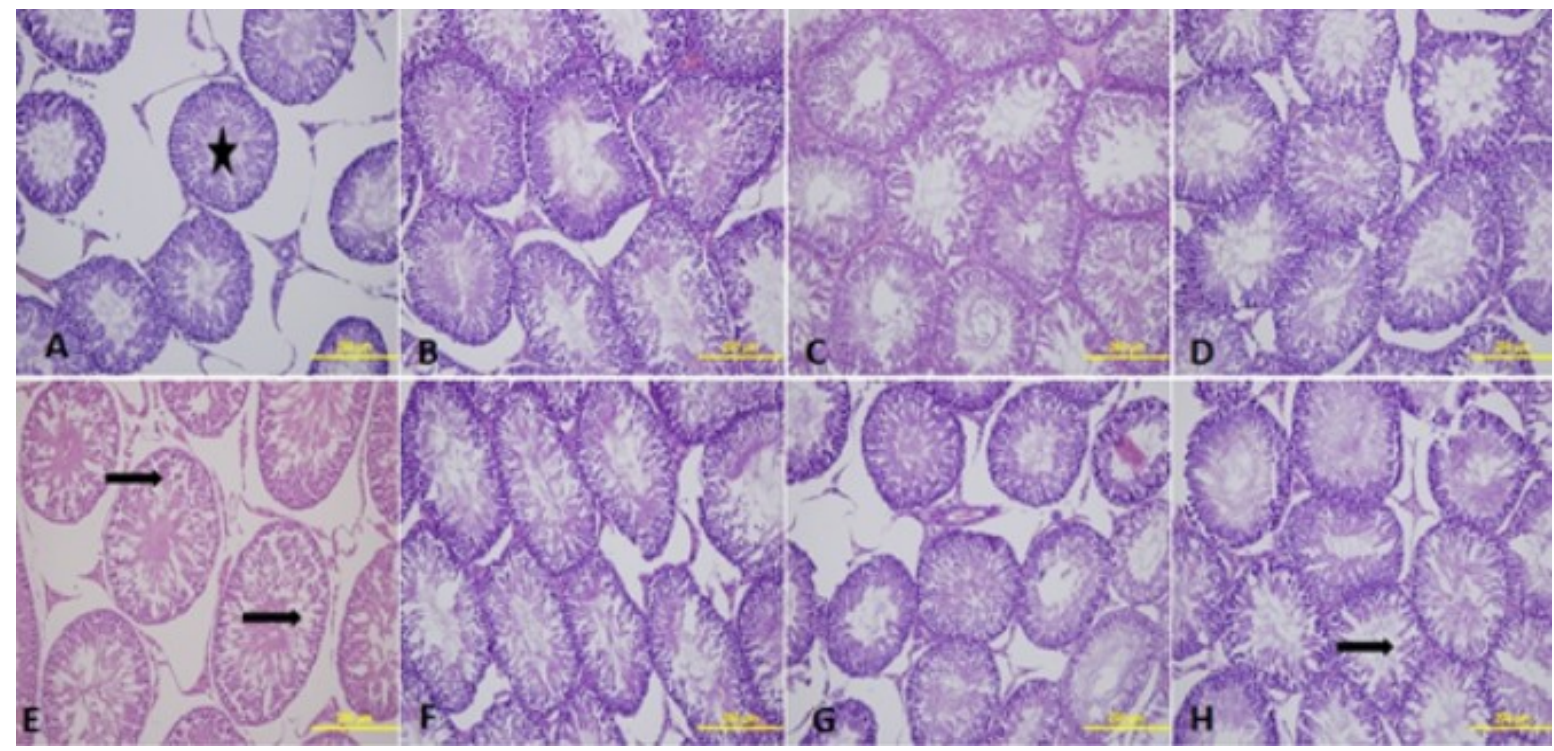

Fig. 3. (A) Normal seminiferous tubule in the control group (star). Seminiferous tubule degeneration and epididymis tissues in the (B) OEP1, (C) OEP2, (D) OEP1+CP, (E) CP, (F) OEP2+CP, (G) CP+OEP1, and (H) CP+OEP2 groups (arrows) (H\&E X200)

The authors reported that both bee pollen and propolis provided significant protection against $\mathrm{CP}$, leading to a significant decrease in the lipid peroxidation level and a significant increase in both glutathione content and catalase activity. Propolis and its compounds such as caffeic acid, galangin, quercetin, and chrysin have been extensively shown to have a protective role against ROS (25). For instance, Kart et al. reported that CAPE, an active component of propolis, exerted a protective effect against $\mathrm{CP}$-induced hepatotoxicity and normalized the tissue glutathione (GSH) level and xanthine oxidase (XO) activity (26). Moreover, although histopathological alterations such as necrosis in hepatocytes, mononuclear cell infiltration, Kupffer cell proliferation, sinusoidal congestion, and hydropic degenerations were observed in the $\mathrm{CP}$ group, these alterations were less frequent in the $\mathrm{CP}+\mathrm{CAPE}$ group. The increased $\mathrm{XO}$ activity induced by $\mathrm{CP}$ leads to increased production of superoxide and hydrogen peroxide, both of which are responsible for the toxic effects of CP. A previous study demonstrated that CAPE decreased XO activity and ameliorated CP-induced ototoxicity (27). In our study, combined administration of CP and OEP resulted in a histological structure like that of control group in the $\mathrm{OEP} 1+\mathrm{CP}, \mathrm{OEP} 2+\mathrm{CP}, \mathrm{CP}+\mathrm{OEP} 1$, and $\mathrm{CP}+\mathrm{OEP} 2$ groups. The adverse effects of $\mathrm{CP}$ on the histological structure of kidney, liver, and testis have been extensively documented. Shirwaikar et al. reported that the administration of CP $(5 \mathrm{mg} / \mathrm{kg} \mathrm{bw})$ in rats resulted in interstitial edema, inflammatory cell infiltration, epithelial degeneration, blood vessel congestion, tubular casts, and glomerular congestion (28). Ozen et al. revealed that CP led to extensive epithelial vacuolization, proximal tubular necrosis, swelling, and tubular dilatation in rat kidney (21). Sawhney et al. showed that CP led to a significant decrease in seminiferous tubular diameter and a severe disruption of seminiferous epithelium and decreased the populations of specific cells and spermatids (29). Nephrotoxicity induced by CP morphologically involves necrosis and apoptosis in proximal tubules of distal nephron (30). Additionally, a previous study reported that $\mathrm{CP}$ led to multiple histopathological alterations including fibrosis necrosis, and hydropic degenerative changes in liver, tubular, and glomerular degeneration with albuminous cast deposition in the kidney as well as a disruption of seminiferous tubular cells with germ cell loss, particularly spermatids and sperms, and congestion of blood vessels in the interstitial tissue of testes (26). Finally, Ceylan et al. argued that CP has a negative effect on the testicles and that these negative effects can be prevented with CAPE (31).

As a conclusion, in addition to its therapeutic effects, $\mathrm{CP}$ was shown to induce toxicity in numerous organs and systems due to its side effects. The presence of these side effects can be confirmed by the aberrations in blood and biochemical parameters. Propolis, a natural product with numerous useful biological effects, was shown to a have protective as well as amelioration and normalizing effect on CP-induced damage. Therefore, future studies conducted with higher doses and a mechanism of action are needed to substantiate our findings.

\section{Conflict of interest}

None to declare.

\section{Acknowledgments}

None to declare.

\section{References}

1. Dasari S, Tchounwou PB. Cisplatin in cancer therapy: molecular mechanisms of action. Eur J Pharmacol. 2014; 740:364-378.

2. Manohar S, Leung N. Cisplatin nephrotoxicity: a review of the literature. J Nephrol. 2018; 31:15-25.

3. Thongnuanjan P, Soodvilai S, Chatsudthipong V, Soodvilai S. 
Fenofibrate reduces cisplatin-induced apoptosis of renal proximal tubular cells via inhibition of JNK and p38 pathways. J Toxicol Sci. 2016; 41:339-49.

4. Quintanilha JCF, Saavedra KF, Visacri MB, Moriel P, Salazar LA. Role of epigenetic mechanisms in cisplatin-induced toxicity. Crit Rev Oncol Hematol. 2019; 137:131-42.

5. Pujirahayu $\mathrm{N}$, Ritonga $\mathrm{H}$, Uslinawaty $\mathrm{Z}$. Properties and flavonoids content in propolis of some extraction method of raw propolis. Int J Pharm Pharm Sci. 2014; 6:338-40.

6. Dantas Silva RP, Machado BA, Barreto GA, Costa SS, Andrade LN, Amaral RG, et al. Antioxidant, antimicrobial, antiparasitic, and cytotoxic properties of various Brazilian propolis extracts. PLoS One. 2017; 12: e0172585.

7. Silici S, Koç NA, Ayangil D, Cankaya S. Antifungal activities of propolis collected by different races of honeybees against yeasts isolated from patients with superficial mycoses. J Pharmacol Sci. 2005; 99: 39-44.

8. Carvalho A, Finger D, Machado CS, Schmidt E. In vivo antitumoral activity and composition of an oil extract of Brazilian propolis. Food Chem. 2011; 126:1239-45.

9. Reis JS, Oliveira GB, Monteiro MC, Machado, CS, Torres YR, Prediger RD, Maia CS. Antidepressant- and anxiolytic like activities of an oil extract of propolis in rats. Phytomedicine. 2014; 21:1466-72.

10. Ramanauskienè K, Inkėnienė, AM. Propolis oil extract: quality analysis and evaluation of its antimicrobial activity. Nat Prod Res. 2011; 25: 1463-8.

11. Sonmez M, Türk, G, Yüce A. The effect of ascorbic acid supplementation on sperm quality, lipid peroxidation and testosterone levels of male Wistar rats. Theriogenology. 2005; 63:2063-72.

12. Johnsen SG. Testicular biopsy score count-a method for registration of spermatogenesis in human testes: normal values and results in 335 hypogonadal males. 1970; Horm Res Paediat. $1: 2-25$.

13. Oun R, Moussa, YE, Wheate NJ. The side effects of platinumbased chemotherapy drugs: a review for chemists. Dalton Trans. 2018; 47(19):6645-53.

14. Dufour P, Bergerat JP, Eber M, Renaud P, Karcher V, Giron C, et al. Cisplatin-induced anemia: a potential interference with iron metabolism at erythroid progenitors level. Colloq Inse. $1990 ; 1: 49-54$.

15. Olas B, Wachowicz B, Majsterek I, Blasiak J. Resveratrol may reduce oxidative stress induced by platinum compounds in human plasma, blood platelets and lymphocytes. Colloq Inse $2005 ; 16: 659-65$.

16. Turan I, Demir S, Misir S, Kılınc K, Mentese A, Aliyaıcıoglu $\mathrm{Y}$, et al. Cytotoxic effect of Turkish propolis on liver, colon, breast, cervix and prostate cancer cell lines. Trop J Pharm Res. 2015; $14: 777-82$.

17. Ibrahim NA. The possible protective effect of bee propolis on experimentally mediated cisplatin reproductive toxicity: a histological and immunohistochemical study. Egypt J Histology. 2013; 36:78-86.
18. Bhargava $\mathrm{P}$, Kumari A, Putri JF, Ishida $\mathrm{Y}$, Terao K, Kaul SC, et al. Caffeic acid phenethyl ester (CAPE) possesses prohypoxia and anti-stress activities: bioinformatics and experimental evidences. Cell Stress Chaperones. 2018; 23: 1055-68.

19. Duan J, Xiaokaiti Y, Fan S, Pan Y, Li X. Direct interaction between caffeic acid phenethyl ester and human neutrophil elastase inhibits the growth and migration of PANC-1 cells. Oncol Rep. 2017; 37: 3019-25.

20. Yilmaz HR, Uz E, Yucel N, Altuntas I, Ozcelik N. Protective effect of caffeic acid phenethyl ester (CAPE) on lipid peroxidation and antioxidant enzymes in diabetic rat liver. $\mathrm{J}$ Biochem Mol Toxic. 2014; 18:234-8.

21. Ozen S, Akyol O, Iraz M, Söğüt S, Ozuğurlu F, Ozyurt H, et al. Role of caffeic acid phenethyl ester, an active component of propolis, against cisplatin-induced nephrotoxicity in rats. J Appl Toxicol. 2004; 24:27-35.

22. Yilmaz HR, Sogut S, Ozyurt B, Ozugurlu F, Sahin S, Isik B, et al. The activities of liver adenosine deaminase, xanthine oxidase, catalase, superoxide dismutase enzymes and the levels of malondialdehyde and nitric oxide after cisplatin toxicity in rats: protective effect of caffeic acid phenethyl ester. Toxicol Ind Health. 2005; 21:67-73.

23. Yılmaz HR, Uz E, Altunbaşak A, Sakallı E, Özçelik N. Anticlastogenic effect of caffeic acid phenethyl ester on cisplatin-induced chromosome aberrations in rat bone marrow cells. Toxicol Ind Health. 2010;. 26:33-7.

24. Tohamy AA, Abdella EM, Ahmed RR, Ahmed YK. Assessment of anti-mutagenic, anti-histopathologic and antioxidant capacities of Egyptian bee pollen and propolis extracts. Cytotechnology. 2014; 66:283-97.

25. Asgharpour F, Moghadamnia AA, Motallebnejad M, Nouri HR. Propolis attenuates lipopolysaccharide-induced inflammatory responses through intracellular ROS and NO levels along with downregulation of IL- $1 \beta$ and IL-6 expressions in murine RAW 264.7 macrophages. J Food Biochem. 2019; 43: e12926.

26. Kart A, Cigremis $Y$, Karaman M, Ozen H. Caffeic acid phenethyl ester (CAPE) ameliorates cisplatin-induced hepatotoxicity in rabbit. Exp Toxicol Pathol. 2010; 62:45-52.

27. Kizilay A, Kalcioglu MT, Ozerol E, Iraz M, Gulec M, Akyol O, et al. Caffeic acid phenethyl ester ameliorated ototoxicity induced by cisplatin in rats. J Chem. 2004; 16:381-7.

28. Shirwaikar A, Deepti Issac D, Malini S. Effect of Aerva lanata on cisplatin and gentamicin models of acute renal failure. $\mathrm{J}$ Ethnopharmacol. 2004; 90:81-6.

29. Sawhney P, Giammona J, Meistrich M, Richburg J. Cisplatininduced long-term failure of spermatogenesis in adult C57/B1/6 J mice. J Androl. 2005; 26:136-45.

30. Manohar S, Leung N. Cisplatin nephrotoxicity: a review of the literature. J Nephrol. 2018; 31:15-25.

31. Ceylan T, Kaymak E, Cantürk Tan, F, Yakan B. Researches on the protective effect of caffeic acid phenethyl ester on testicular damage caused by cisplatin. Turk J Med Sci. 2020; 6. doi: 10.3906/sag-2002-58. 